\title{
The Effect of Technological Parameters on the Formation of Fillet Welds in Two-Electrode Submerged Arc Welding
}

\author{
Mikhail Sholokhov ${ }^{1,2}$, Daria Buzorina ${ }^{1,2 *}$, Anton Melnikov ${ }^{1,2}$, Andrey Fiveyskii ${ }^{1,2}$, and \\ Alexey $\operatorname{Mosin}^{3}$ \\ ${ }^{1}$ Ural Federal University named after the first President of Russia B.N. Yeltsin, 620002, Ekaterinburg, \\ Russia \\ ${ }^{2}$ SHTORM Co.Ltd, 620100, Ekaterinburg, Russia \\ ${ }^{3}$ Kurganstalmost CJSC, 640023, Kurgan, Russia
}

\begin{abstract}
The development of transport infrastructure contributes to an increase in the demand for bridge structures, which leads to the need to increase the productivity of their manufacture. The overall increase in welding productivity is facilitated by an increase in the volume of welds performed in a single pass. It is proposed to use two-electrode welding. Computer analysis of such process has shown that an acceptable fillet weld formation can be ensured by rational parameters of the welding process, including the positioning of the electrodes relative to the weld. The distance between the electrodes should be approximately equal to the required leg size, and the electrodes shall be turned by an angle of $45^{\circ}$ so that the electrode on the web lags behind the one on the flange, and the axis of this electrode is located at a distance equal to half of the required leg, the tilt angle of the torch should be $30^{\circ}$ from vertical. With the indicated positioning of the electrodes, an asymmetrical weld pool is formed, the end of which is strongly displaced to the web. The melt runoff from the web to the flange is limited by the lower boundary of the weld pool, consequently, the finishing of the runoff and solidification of the metal is shifted towards the web. This fact improves the formation of weld surface, reducing the meniscus at the web and the influx on the flange. Thus, the decrease of the meniscus at the web and the influx on the flange when the arc is placed on the web can be explained by the asymmetric process of metal solidification, which proceeds predominantly from the flange to the web.
\end{abstract}

\section{Introduction}

Today, the issue of creating and developing a transport system and infrastructure continues to be relevant, in connection with which the development of bridge construction in Russia continues. At the same time, the share of metal bridges in the total number of technical structures on roads and railways is increasing every year.

\footnotetext{
*Corresponding author: darja.buzorina@yandex.ru
} 
One of the important advantages of steel bridges is the possibility of maximum industrialization of their manufacture, the implementation of high-performance methods of automatic welding, high quality and the amount of pre-fabricated structures, as well as the possibility of complex mechanization, year-round performance and assembling a short period of time [1].

A special feature of the parts of three-dimensional metal structures welded in the workshop is a large share in the total volume of welding works of extended seams (more than $2 \mathrm{~m}$ in length) - up to 55-60\% (according to the data of CJSC "Kurganstalmost"). In this case, fillet welds account for $40 \%$ to $70 \%$ of the total amount of the weld seams.

Taking into account the increasing demand for bridge structures, it becomes necessary to search for opportunities to increase the productivity of metal structures production. The overall increase in welding productivity is facilitated by an increase in the volume of welds performed in a single pass.[2].

Traditionally fillet welds with the leg of $8 \mathrm{~mm}$ are produced under single pass automatic submerged arc welding, but the welds with the larger leg require several passes in $2 \mathrm{~F}$ position or in $1 \mathrm{~F}$ position. However when welding large and heavy metal structures, it is often impossible to use the positioners necessary for welding in $1 \mathrm{~F}$ position, therefore the vast majority of seams are welded in $2 \mathrm{~F}$ position. It is known that it is possible to obtain guaranteed long seams of the required quality in single-pass submerged-arc welding only with a leg of 6-7 $\mathrm{mm}$. With large legs, an acceptable weld formation during welding in one pass cannot be obtained due to the flow of metal from the web.

One of the options for increasing the productivity of welding is two-electrode welding, which makes it possible to increase the leg of fillet welds when welding in $2 \mathrm{~F}$ position with a satisfactory quality of their formation due to the complex electrodynamic effect on the weld pool of the arc with two electrodes $[2,3]$.

It is known that there is a multiparameter dependence between the position of the electrodes in the welded joint, the modes of two-electrode welding and the quality of fillet welds of three-dimensional bridge metal structures, but until now there is no mathematical description of the features of the formation of fillet welds in two-electrode submerged arc welding.

An engineering analysis of the influence of the parameters of two-electrode welding on the quality of welded joints is needed, it is also necessary to complete a comprehensive study of the features of automatic two-electrode welding of bridge metal structures, which will allow to develop cost-effective processes of two-electrode welding of fillet welds and the necessary welding equipment for the industrial production of three-dimensional bridge metal structures.

\section{Requirements imposed on fillet welds}

The main regulatory document governing the factory production of metal structures for bridges is a standard of "Transstroy" State Corporation -012 [4].

Depending on the design, operating conditions and installation of the span, the welded joints of bridge structures are divided into categories I, II and III. Welds of all categories undergo visual and dimensional inspection. $100 \%$ of category I seams are subjected to ultrasonic testing (SPL).

For all categories of welds, unacceptable surface defects are cracks of all types, sizes and alignment, burn-throughs, surface porosity, local damage due to arc ignition outside the seam, splashes tightly adhered to the surface, surface damage caused by the removal of temporary devices (to be corrected), local unevenness of seam surface at the point of reignition of the arc [4]. 
Inadmissible internal defects for all categories of welds are cracks of all types, sizes and alignment, accumulations and chains of internal pores, gas cavities and / or slag inclusions, inclusions of copper, bronze, tungsten and other metal.

In addition special attention should be paid to the geometry of fillet welds, since it is the geometry of the transition zone from the seam to the base metal according to the study $[5,6]$ that determines the stress condition in the given structure zone and, therefore, affects the durability of the welded joint [1]. The special feature of the fillet weld formation under welding in $2 \mathrm{~F}$ position is due to the gravity force, which is directed asymmetrically relative to the legs of the seam. In this regard, the forming fillet weld in most cases will have asymmetry, which is caused by the gravity force, which increases with an increase in the amount of deposited metal.

The configuration of a single-pass fillet weld is determined by such parameters as the legs of the outer part of the seam $k$, penetration depth at the junction of the parts to be welded $s$, calculated parameter of the seam $l$, effective throat $h$, bead width $e$ (Fig. 1, a), weld shape ratio (weld penetration shape factor) $\psi$, penetration area of the base metal, area of the outer part of the seam and total seam area [7].

a)

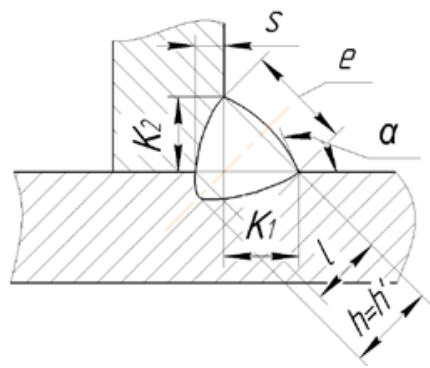

c)

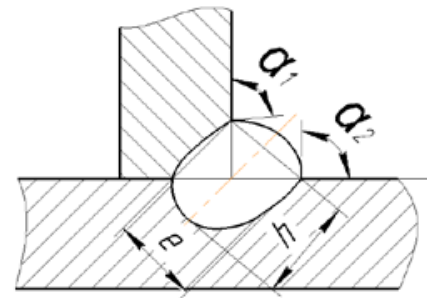

b)

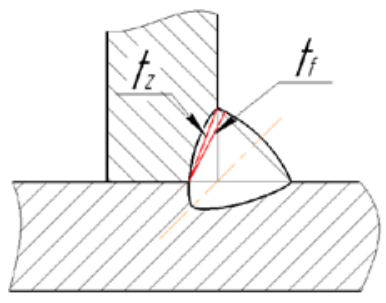

d)

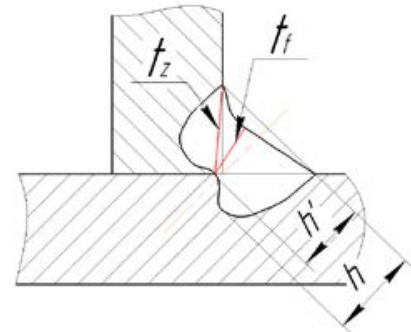

Fig. 1.Schematic for determining the dimensions of the cross section of the welded seam in accordance with a standard of "Transstroy" State Corporation -012-2018: a) dimensions of the weld b) determination of the calculated height of the cross section of the weld metal $t_{f}$ and of the metal of the fusion boundary $t_{z} ;$ c) surface matching of the weld reinforcement with the base metal; d) irregular shape of the penetration

To fulfill the strength condition, the calculated height of the cross section for the weld metal $t_{f}=\beta_{f} \cdot k_{f}$ and of the metal of the fusion boundary $t_{z}=\beta_{z} \cdot k_{f}$, must be ensured, where $k_{f}$ is the smallest of the legs of the fillet weld, specified by the leg of the inscribed triangle; $\beta_{f}$, $\beta_{z}$ - coefficients of calculated sections of fillet welds (according to [8] for automatic submerged-arc welding with a wire of a diameter 2-5 mm, if weld legs 9-12 mm take up $\beta_{f}$ $=0,9, \beta_{z}=1,05$, ifweld legs $3-8 \mathrm{~mm}$ take up $\left.-\beta f=1.1, \beta z=1.15\right)$ (Fig. $\left.1, \mathrm{~b}\right)$.

Fillet welds quality criteria [4]:

1) weld penetration shape factor $\varphi_{\text {пр }}$ should amount to $\varphi_{\text {пр }}=\mathrm{e} / \mathrm{h} \geq 1,2$, whereas the penetration should be symmetrical on both sides of toes (dimensions of the weld are given in Fig. 1, a);

2) excessive weld reinforcement should be not greater than $2 \mathrm{~mm}$; 
3) surface matching of weld reinforcement with the main metal should be $\alpha \geq 100^{\circ}$ (Fig. 1, c);

4) an undercut of more than $1 \mathrm{~mm}$ requires subsequent welding with scraping;

5) the asymmetry of the fillet weld $h$ shall be $\leq 1+0,1 \mathrm{k}$;

6) the concavity of the seam shall be no more than $30 \%$ from the weld leg, but not greater than $3 \mathrm{~mm}$;

7) the calculated height of the cross section for the weld metal $t_{f}=\beta_{f^{*}} k_{f}$ and of the metal of the fusion boundary $t_{z}=\beta_{z} \cdot k_{f}$, shall be ensured, where $k_{f}$ is the smallest of the legs of the fillet weld, specified by the leg of the inscribed triangle; $\beta_{f}, \beta_{z}$ - coefficients of calculated sections of fillet welds (for the case under consideration according to the handbook of instructions $35.13330 \beta_{f}=0,9, \beta_{z}=1,05$ ) (Fig. 1, b);

8) irregular shape of penetration. Penetration depth along the weld axis $h$ 'shall not be less than the maximum penetration depth $h\left(h^{\prime} \geq h\right)$ (Fig. 1, d).

\section{Research}

To analyze the influence of the parameters of two-electrode welding on the formation of submerged arc fillet welds executed in $2 \mathrm{~F}$ position, we used the physico-mathematical model of the seam formation during submerged arc welding, developed by the authors. [9].

The model takes into account that the arc burns in a vapor-gas cavity resulting from the melting and evaporation of the flux. It is taken into account that the heat of arcs spreads in a complex space, including the joint metal in solid and liquid states, flux in powder, molten and remelted states. In addition to molecular heat transfer, the model takes into account the transfer of heat by flux fumes within the gas-arc cavity and electrode metal droplet transfer, and also determines the location of the arc in the specified cavity. The shape of the surface of the weld pool and seam is determined by calculating the curvature of this surface, which balances the gravitational pressure, determined by the spatial position, as well as the electrodynamic pressure of the arc and the internal pressure in the melt. The value of the internal pressure is determined from the condition of mass balance of the deposited and electrode metal. The system of equations describing the listed phenomena is solved by numerical methods. With a computing solution, arc heat distribution in the metal and flux is calculated, the location of the weld pool and the shape of its surface, which is fixed at the solidification front, which specifies the formation of the weld, is determined.

To reproduce two-electrode welding, a description of the spatial position of the electrodes (welding wires) relative to the joint was added to the model described above, and the distribution of the heat flux and arc pressure at two electrodes was specified. Accordingly, additional parameters were introduced into the model: the distance $g$ between the electrodes, the angle $\beta$ between the surface of the electrodes and the direction of welding, and the distance $r$ from the electrode to the midline of the joint. The influence of the angle of inclination of the torch $\alpha$ relative to the joint was also taken into account.

The performed analysis showed that the melt runoff in two-electrode welding in $2 \mathrm{~F}$ position can be prevented by a certain positioning of the electrodes relative to the joint. This will allow to increase the size of the legs of fillet welds under single-pass welding with a satisfactory formation. To do this, it is necessary to have a distance between the electrodes approximately equal to the required leg size, and the electrodes shall be turned by an angle of $45^{\circ}$ so that the electrode on the web lags behind the one on the flange, and the axis of this electrode is located at a distance equal to half of the required leg. It is efficient to have a $30^{\circ}$ tilt angle of the torch from vertical. The arc current and speed shall be selected based on the required penetration. 
Physical explanation of the effectiveness of this solution can be given as follows: the displacement of the arc on the web leads to the creation of a weld pool of non-equilibrium shape (Fig. 2).
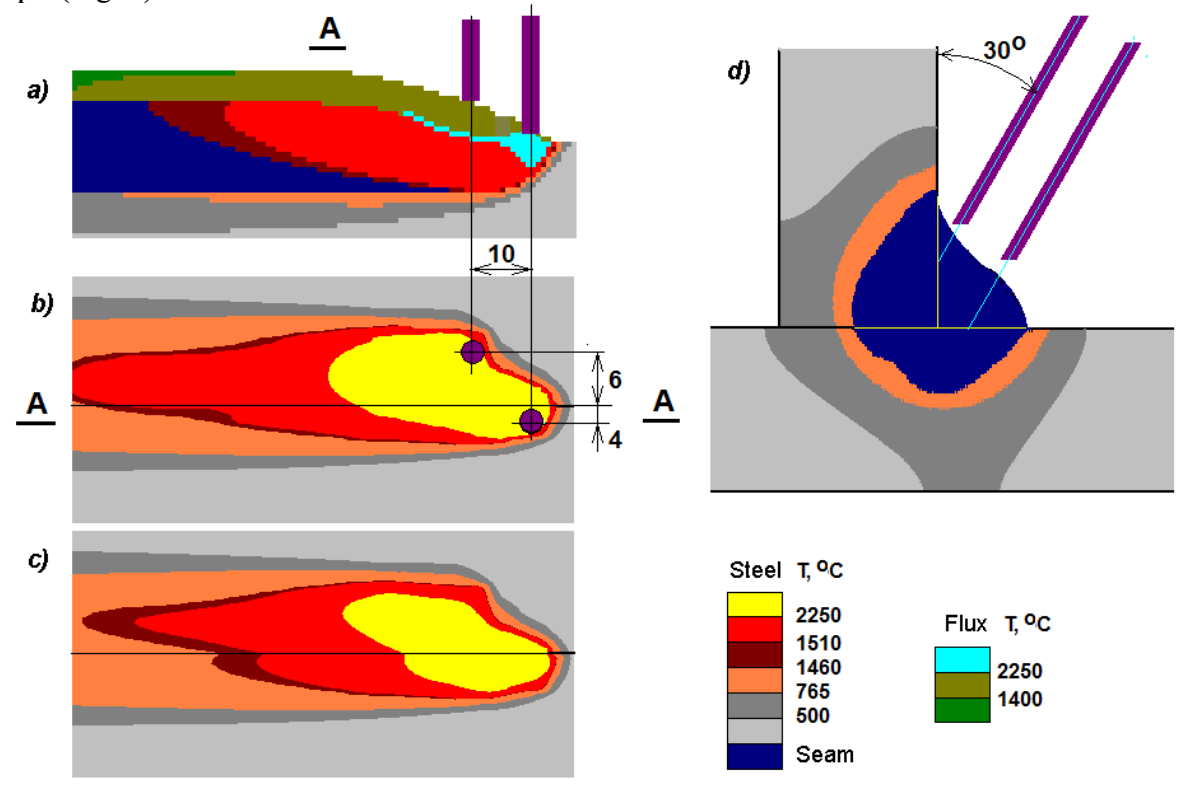

Fig. 2. The simulation result of the weld pool formation with the selected welding parameters: a) temperature partitioning in the longitudinal cross section; b) on the metal surface; c) on the original surface of work; d) the calculated shape of the seam and the position of the electrodes

The part of the weld pool created by the arc on the flange is shorter than the part created by the arc on the web, since the heat dissipation in a flange is more significant than in the web. In addition, the arc on the web melts the metal heated by the upper arc located on the flange. With the indicated positioning of the electrodes, an asymmetrical weld pool is formed, the end of which is strongly displaced to the web. The melt runoff from the web to the flange is limited by the lower boundary of the weld pool, consequently, the finishing of the runoff and solidification of the metal is shifted towards the web. This fact improves the formation of weld surface, reducing the meniscus at the web and the influx on the flange. Thus, the decrease of the meniscus at the web and the influx on the flange when the arc is displaced on the web is explained by the asymmetric process of metal solidification, which proceeds predominantly from the flange to the web.

\section{Results}

The verification of the developed model and the assessment of the quality of welded joints was carried out in accordance with the existing regulated criteria for the absence of defects based on a standard of "Transstroy" State Corporation -012-2018», handbook of instructions 35.13330 [8], GOST 30242-97 [10], and also a comparison of theoretical and practical geometry formation of welded seams has been carried out.

Welding mode parameters: electrode wire Sv-08GA with a diameter of $2 \mathrm{~mm}$, feed rate $23 \mathrm{~mm} / \mathrm{s}$, electrode stick-out $25 \mathrm{~mm}$, welding speed $10 \mathrm{~mm} / \mathrm{s}$, welding current $850 \mathrm{~A}$, welding voltage $29 \mathrm{~V}$. Parameters of electrode disposition relative to the joint: $\alpha=30^{\circ}, r=-$ $3 \mathrm{~mm}$. 
Comparison of the simulation results with macrosections of welded samples with electrodes located at different angles relative to the joint $\beta$ and change in the distance between the electrodes $g$ are shown in Fig. 3 .

1)

a)

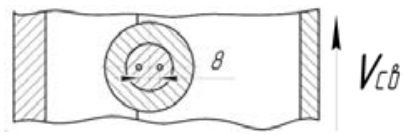

b)

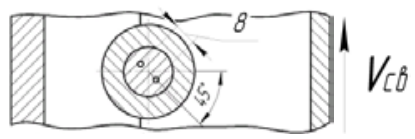

c)

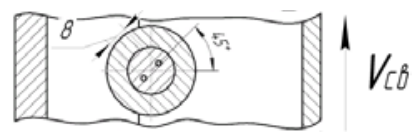

d)

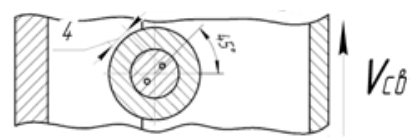

e)

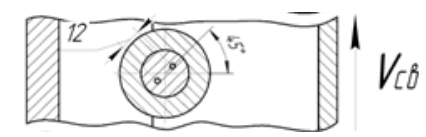

2)
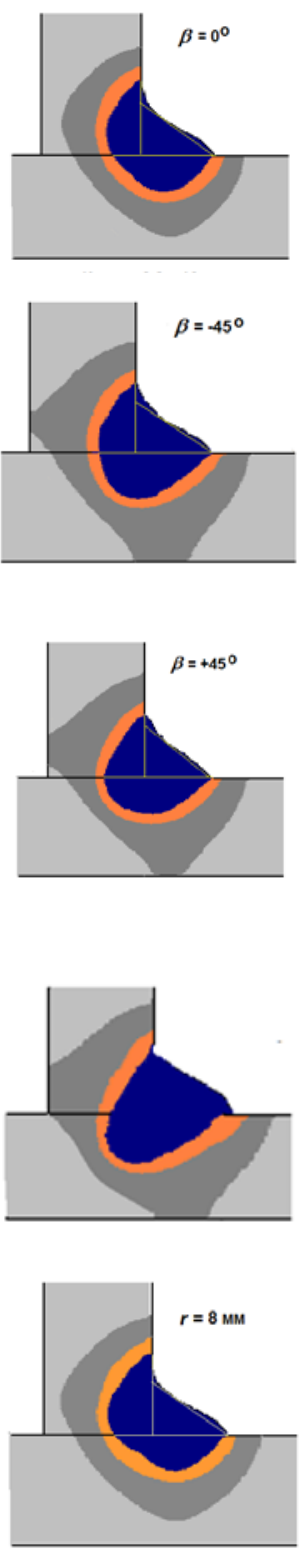

3)
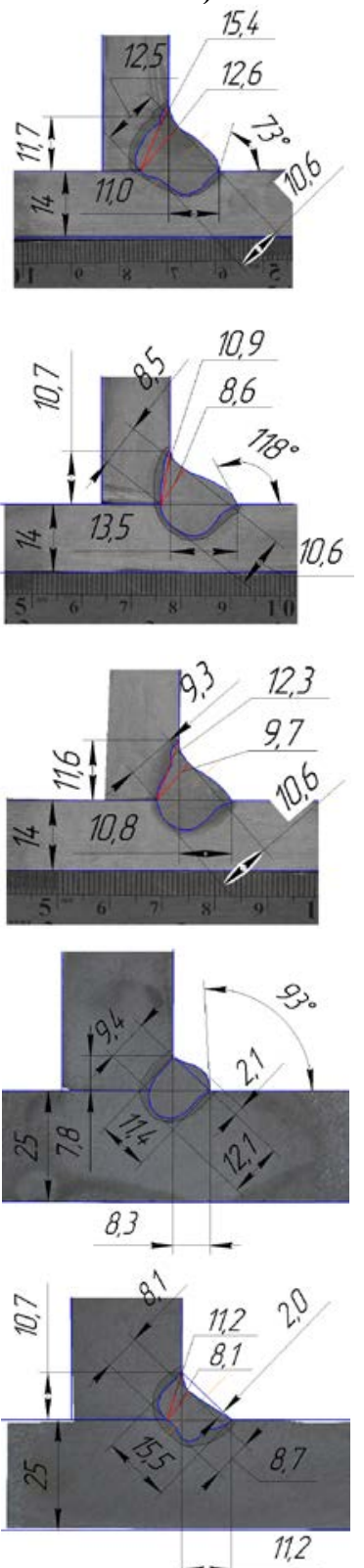

Fig. 3. Comparison of simulation results with microsections of welded samples when changing the angle of the electrodes relative to the butt joint $\beta$ and the distance between the electrodes $g$ : a) $\mathrm{g}=8$ $\left.\left.\left.\left.\mathrm{mm}, \beta=0^{\circ}, \mathrm{b}\right) \mathrm{g}=8 \mathrm{~mm}, \beta=+45^{\circ}, \mathrm{c}\right) \mathrm{g}=8 \mathrm{~mm}, \beta=-45^{\circ}, \mathrm{d}\right) \mathrm{g}=4 \mathrm{~mm}, \beta=-45^{\circ}, \mathrm{e}\right) \mathrm{g}=12 \mathrm{~mm}, \beta$ $=45^{\circ}$; 1) the layout of the electrodes, 2) the simulation result of the shape of penetration; 3 ) macrosection of the welded sample 
When the electrodes are placed on a line perpendicular to the direction of welding, a wide seam is formed with noticeable runoff of the melt from the web (Fig. 3, a). In this case, the seam is formed with an irregular penetration depth $(\mathrm{h} '<\mathrm{h})$ and with an unacceptable surface matching of the weld reinforcement with the base metal $\alpha \leq 100^{\circ}$ (influx). The penetration of the joint between the web and the flange does not reach half the web thickness. When the electrode on the web is displaced forward $\left(\beta=-45^{\circ}\right)$ (Fig. 3, b) and, accordingly, the electrode lags on the flange, the penetration depth increases, which is explained by the approach of the arcs to the plane of symmetry of the joint. However, only the penetration of the flange increases, and the penetration of the joint between the web and the flange decreases. Weld seam is formed with the unacceptable asymmetry $(\geq 1+0,1 \kappa)$, the calculated height of the cross section of the weld metal: $t_{f}=8,6 \leq 9.6$ and of the metal of the fusion boundary $t_{\mathrm{z}}=10,9 \leq 11.23$ are not provided. When the arc on the web is displaced backwards $\left(\beta=+45^{\circ}\right)$ (Fig. 3, c), at which the arc on the web lags behind the arc on the flange, the melt runoff and the difference of legs are noticeably reduced. There are no unacceptable defects.

Since the arrangement variant with the arc lagging on the web provides the best formation of the seam, further research of the influence of the distance between the electrodes was performed for this variant.

When the distance between the electrodes is $4 \mathrm{~mm}$ (Fig. 3, d) we can notice a phenomenon similar to the one when we weld with an electrode of a larger diameter with a high current density, which leads to deep penetration and a decrease in the width of the weld, an increase in convexification (unacceptable angles matching of the weld reinforcement with the base metal). When the distance between the electrodes is $12 \mathrm{~mm}$ (Fig. 3, e) we can notice the separation of weld pool into two parts, which leads to a deviation of the shape of penetration and asymmetry of the weld.

The analysis of the obtained results confirmed the correctness of the theoretical conclusions, and practical verification - the adequacy of the simulation results.

\section{Conclusions}

1. The developed mathematical model of the submerged arc welding process based on the equations of thermal conductivity and the formation of the weld pool surface is supplemented by ratios that take into account the effect of two electrodes and their location relative to the joint.

2. Simulation has shown that during the production of a fillet weld in $2 \mathrm{~F}$ position, it is possible to provide a satisfactory formation of a seam with a leg up to $12 \mathrm{~mm}$ with a certain positioning of the electrodes relative to the joint, in which the electrode on the web lags behind the electrode on the flange. The efficient distance between the electrodes is $8 \mathrm{~mm}$, the angle of rotation of the electrodes relative to the welding direction is $45^{\circ}$, the displacement of the electrode from the joint line is $4 \mathrm{~mm}$, the angle of inclination of the torch is $30^{\circ}$.

The assistance provided by the translator of the present article Ms. Natalia Karamysheva was greatly appreciated.

\section{References}

1. N.O. Okerblom, V.P. Demyantsevich, I.P. Baykova, Proyektirovaniye tekhnologii izgotovleniya svarnykh konstruktsiy (raschetnyye metody) (Sudpromgiz, Leningrad, 1963) 
2. A.A. Mosin, Vozmozhnosti povysheniya proizvoditel'nosti svarki protyazhennykh uglovykh shvov mostovykh metallokonstruktsiy [Ways to solve problems of increasing the efficiency of welding long corner seams of three-dimensional metal structures], Сварка и диагностика [Welding and diagnostics], № 1, pp. 50-54 (2020)

3. A. Fiveyskiy, A. Mosin, S. Zverev, I. Polevoy, Research on technological capabilities of double-electrode welding of long fillet welds, Matec Web of Conferences. The proceedings International Conference on Modern Trends in Manufacturing Technologies and Equipment: Mechanical Engineering and Materials Science (ICMTMTE 2019), v. 298(25), p. 00072 (2019)

4. Stal'nyye konstruktsii mostov. Zavodskoye izgotovleniye (Transstroyizdat, 2007)

5. A. Parkhomenko, Statisticheskiy obraz geometrii profilya perekhoda ot shva $k$ osnovnomu metallu uglovykh shvov [Statistical image of geometry a structure of toe for angular seams], Vestnik DGTU [Advanced Engineering Research], № S2, pp. 111-118 (2009)

6. B.M. Berezovskiy, Matematicheskiye modeli dugovoy svarki. V. 2. Matematicheskoye modelirovaniye i optimizatsiya formirovaniya razlichnykh tipov svarnykh shvov (Izd-vo YUUrGU, Chelyabinsk, 2003)

7. B.E. Paton, Tekhnologiya elektricheskoy svarki metallov i splavov plavleniyem (Mashinostroyeniye, 1974)

8. CП 35.13330.2011 Mosty i truby (2011)

9. A.A. Mosin, V.A. Erofeev, M.A. Sholokhov, Fiziko-matematicheskoye modelirovaniye osobennostey formirovaniya uglovykh shvov pri dugovoy svarke pod flyusom mostovykh metallokonstruktsiy [Physicomathematical modeling of the formation features of fillet welds of bridge metal structures under submerged-arc welding], Advanced Engineering Research, № 2, pp. 259-268 (2020)

10. GOST 30242-97. Defekty soyedineniy pri svarke metallov plavleniyem. Klassifikatsiya, oboznacheniye i opredeleniya (1997) 